\title{
Assessing the Medical Teacher's Role in Practicing Instructional Events in the Lecture Classes of Selected Medical Colleges
}

\author{
Rahman $\mathrm{MM}^{1}$, Talukder $\mathrm{MHK}^{2}$, Ferdousi $\mathrm{S}^{3}$, Habib $\mathrm{MA}^{4}, \mathrm{Alam}_{\mathrm{MKK}}^{5}, \mathrm{Kabir}_{\mathrm{MF}}^{6}$
}

\begin{abstract}
Introduction: Lecture is an important method of instruction through which the undergraduate medical students acquire knowledge, experience, skill and attitude. There are however, serious questions regarding the effectiveness of the traditional lecture approach. Yet, it is agreed upon that this can be more effective by making this approach methodical and more interactive.
\end{abstract}

Objectives: This study was conducted to assess medical teachers' skills in instructional events in their lecture classes.

Materials and Methods: A descriptive, crosssectional study was conducted from July 2013 to June 2014 at conveniently selected six medical colleges of the country. At those selected institutions 30 lecture classes were observed and views of 1500 students were collected. A checklist with rating scale having rubric was used by the researchers to record the necessary observations while attending the lectures covering 8 instructional events. Out of 30 lecture classes, 13 were of preclinical subjects and 17 were of paraclinical area. Views of 1500 students were collected on a self administered structured questionnaire just after attending observed classes, covering 11 areas of performance. Out of them 732 were preclinical students and 768 were paraclinical students.

Results: In this study, majority of the respondents $(67 \%)$ agreed that the teachers successfully gained attention. In mentioning objective, the observer marked more than half $(53.3 \%)$ of the teachers as unsatisfactory. The mean score of observer's opinion in mentioning objective was $0.97 \pm 1.35$. More than one fourth $(23.55 \%)$ of the student respondents did not agree that the teachers stimulated prior knowledge in the lecture class. More than one fourth $(26.15 \%)$ of the respondents did not agree that necessary feedback were taken by the teachers. Forty two percent of the respondents did not agree that the teachers provided a good summary at the end. More than one fourth of the respondents $(26.85 \%)$ did not agree that the lecture was interesting. In this study, some of the key performances of the teachers like mentioning objective of the lesson, providing summary, legibility of teaching aids were scored less than 2, indicating that those were the problem areas and should be emphasized more. In this regards, continued medical education/continued professional developmental program of medical colleges should be valued and exercised properly.

Conclusion: Effectiveness of a lecture largely depends on the knowledge of the teachers in teaching methodologies, their individual skills in presentation and their ability in classroom management. This study revealed that the teachers of medical colleges had been missing some important characteristics of effective lecture.

Key-words: Teacher, Lecture, Instructional Event.

\section{Introduction}

The process involved in an act of learning, to a large extent, is activated internally. This internal process is influenced by external events and this is what makes instruction possible. Typically instruction consists of events external to the learner designed to support the internal process of learning. Lecture is one of the important teaching methods in medical education".

1. Brig Gen Md Mahbubur Rahman, MBBS, MCPS, DPH, M MEd, Commandant, CMH, Dhaka; 2. Prof Dr Md Humayun Kabir Talukder, MBBS, MPH, PGDM, MSC (HPED), Professor of Curriculum Development, Centre for Medical Education (CME); 3. Dr. Shahnila Ferdousi, MBBS, M Phil (PSM), MD (Clinical Biochemistry), Associate Professor, Department of Biochemistry, Dhaka Medical College; 4. Brig Gen Md Ahsan Habib, MBBS, M Phil, M MEd, Head, Dept of Anatomy, AFMC, Dhaka; 5. Dr Md Kazi Khairul Alam, MBBS, Assistant Professor of Medical Education, CME; 6. Col Md Fazlul Kabir, MBBS, MPhil (Health Care Management) Additional Inspector General of Prison, Dhaka. 
Gibbs et $\mathrm{al}^{2}$ stated that despite moving away from teacher centered methods towards more independent student-centered learning, resource pressure will continue to require the use of large lecture classes. In a lecture class instructional events like gaining attention, Informing the learner the objective of the session, stimulating recall of prerequisite knowledge, organization of the lecture, teaching aids used by the teachers, legibility of the teaching aids, feedback taken by the teachers and summary provided by the teachers play important role in student's learning ${ }^{3,4}$. In the present study, an effort has been made to assess the extent the medical teachers have been practicing these instructional events in their lecture classes.

\section{Materials and Methods}

This descriptive cross sectional study was carried out from July 2013 to June 2014 involving six medical colleges among which three were government and three were private, selected through convenient sampling. Out of the six medical colleges, 4 were in Dhaka city and 2 were at Mymensingh. In the Dhaka city the government medical colleges were Sir Salimullah Medical College and Armed Forces Medical College and non-government medical colleges were Bangladesh Medical College and Delta Medical College. Outside Dhaka city, the government medical college was Mymensingh Medical College and the non-government medical college was Community Based Medical College. At those selected institutions 30 lecture classes were observed and views of 1500 students were collected. A checklist with rating scale having rubric was used by the researchers to record the necessary observations while attending the lectures. Out of 30 lecture classes 13 were of preclinical subjects and 17 were of paraclinical area. Views of 1500 students, who attended the classes, were collected on a self administered structured questionnaire and of them 732 were preclinical students and 768 were paraclinical students. During development of students questionnaire "The Dundee Ready Education Environment Measure (DREEM)" inventories were studied and adopted in an improvised manner. The interpretation of the findings was also in line with "DREEM".

The questionnaire for the students comprised of 28 separate positive statements regarding teacher's performance $($ Excellent $=4$, Very good $=3$, Good $=2$, Fair= 1, Unsatisfactory=0) in the lecture class. Each statement was followed by five options with rating scale (Strongly disagree $=0$, Disagree $=1$, Neither agree nor disagree $=2$, Agree $=3$ and Strongly agree=4). After completion of data collection, the questionnaire used for the students were serially numbered from 1-1500. Checklist for the observers was serially numbered from 1-30. Result of the variables were calculated in excel sheet and data were transferred to SPSS version 19 for analysis. Classification, tabulation, measurement of central tendency, comparison and correlation of the values were done as applicable. For interpretation of the scores, items that have a mean score of 3.5 or more were considered as real positive points. Any item with a mean score of 2 or less was indicated as problem area. Items with a mean of 2-3 were identified as the areas that need to improve.

\section{Results}

Majority of the teachers were having teaching experience $(33.33 \%)$ of $5-10$ years (Table-I) and underwent training $(76.67 \%)$ in teaching methodologies (Table-II).

Table-I: Distribution of teachers by their teaching experience $(n=30)$.

\begin{tabular}{|l|c|}
\hline Teaching experience (years) & Number (\%) \\
\hline $5-10$ & $10(33.33)$ \\
\hline $10-15$ & $07(23.33)$ \\
\hline $15-20$ & $05(16.67)$ \\
\hline More than 20 & $08(26.67)$ \\
\hline
\end{tabular}

Table-II: Distribution of teachers by their training on teaching methodology $(n=30)$.

\begin{tabular}{|l|c|}
\hline $\begin{array}{l}\text { Degree/Training on } \\
\text { teaching methodology }\end{array}$ & Number (\%) \\
\hline $\begin{array}{l}\text { Workshop on teaching } \\
\text { methodology/Assessment }\end{array}$ & $23(76.67)$ \\
\hline $\begin{array}{l}\text { No degree or workshop on } \\
\text { teaching methodology/ Assessment }\end{array}$ & $07(33.33)$ \\
\hline
\end{tabular}

As per the student's view on the teachers' performance on practicing instructional events was inclined towards the agreements (Table-III) with the mean score ranging from 2.03 to 2.93. Students' perception on outcome of lecture attended was also towards the agreement (Table-IV) and the mean ranged from 2.3 to 2.79 . 
Table-III: Distribution of respondents by their response on teacher's performance on practicing instructional events $(n=1500)$.

\begin{tabular}{|l|c|c|c|c|c|c|}
\hline \multirow{2}{*}{ Area of performance } & \multicolumn{6}{|c|}{ Student's views } \\
\cline { 2 - 7 } & $\begin{array}{c}\text { SDA } \\
\mathrm{f}(\%)\end{array}$ & $\begin{array}{c}\text { DA } \\
\mathrm{f}(\%)\end{array}$ & $\begin{array}{c}\text { NAND } \\
\mathrm{f}(\%)\end{array}$ & $\begin{array}{c}\text { A } \\
(\%)\end{array}$ & $\begin{array}{c}\text { SA } \\
\mathrm{f} \%)\end{array}$ & $\begin{array}{c}\text { Score } \\
\text { Mean } \pm \text { SD }\end{array}$ \\
\hline Teachers successfully gained attention & $139(9.3)$ & $207(13.8)$ & $149(9.9)$ & $686(45.7)$ & $319(21.3)$ & $2.56 \pm 1.23$ \\
\hline Objective of the lesson was clear & $99(6.6)$ & $301(20.1)$ & $165(11.0)$ & $640(42.7)$ & $295(19.7)$ & $2.49 \pm 1.20$ \\
\hline Teachers stimulated prerequisite knowledge & $94(6.3)$ & $258(17.2)$ & $167(11.1)$ & $733(48.9)$ & $248(16.5)$ & $2.52 \pm 1.41$ \\
\hline Teaching was legible & $93(6.20)$ & $125(8.3)$ & $113(7.5)$ & $631(42.1)$ & $538(35.9)$ & $2.93 \pm 1.15$ \\
\hline Teaching aids used facilitated learning & $79(5.3)$ & $154(10.3)$ & $210(14.0)$ & $736(49.1)$ & $321(21.4)$ & $2.71 \pm 1.08$ \\
\hline Teachers took necessary feedback & $138(9.2)$ & $253(16.9)$ & $107(7.1)$ & $620(41.3)$ & $382(25.5)$ & $2.57 \pm 1.28$ \\
\hline Teachers provided good summary & $168(11.2)$ & $460(30.7)$ & $237(15.8)$ & $429(28.6)$ & $206(13.7)$ & $2.03 \pm 1.26$ \\
\hline
\end{tabular}

NB: SDA= Strongly Disagree (Score=0), DA= Disagree (Score=1), NAND= neither Agree nor Disagree (Score=2), A= Agree (Score=3), SA= Strongly Agree (Score=4).

Table-IV: Distribution of respondents by their response on outcome of the lecture.

\begin{tabular}{|l|c|c|c|c|c|c|}
\hline \multirow{2}{*}{ Item } & \multicolumn{5}{|c|}{ Student's perception } \\
\cline { 2 - 7 } & $\begin{array}{c}\text { SDA } \\
\mathrm{f}(\%)\end{array}$ & $\begin{array}{c}\text { DA } \\
\mathrm{f}(\%)\end{array}$ & $\begin{array}{c}\text { NAND } \\
\mathrm{f}(\%)\end{array}$ & $\begin{array}{c}\mathrm{A} \\
\mathrm{f}(\%)\end{array}$ & $\begin{array}{c}\text { SA } \\
\mathrm{f}(\%)\end{array}$ & $\begin{array}{c}\text { Score } \\
\text { Mean } \pm \text { SD }\end{array}$ \\
\hline Lecture was interesting & $164(10.9)$ & $239(15.9)$ & $320(21.3)$ & $540(36.0)$ & $237(15.8)$ & $2.30 \pm 1.22$ \\
\hline Kept the students attentive & $162(10.8)$ & $295(19.7)$ & $286(19.1)$ & $507(33.8)$ & $250(16.7)$ & $2.26 \pm 1.25$ \\
\hline Students were very much satisfied with the conduction of lecture & $167(11.1)$ & $233(15.5)$ & $384(25.6)$ & $478(31.9)$ & $238(15.9)$ & $2.26 \pm 1.22$ \\
\hline Lecture class was beneficial to the students & $102(6.8)$ & $87(5.8)$ & $211(14.1)$ & $727(48.5)$ & $373(24.9)$ & $2.79 \pm 1.09$ \\
\hline
\end{tabular}

Observers' opinion showed that $53.3 \%$ of the performance in informing objective of the lecture was unsatisfactory (Table-V). Unsatisfactory performances were observed in $30 \%$ and $20 \%$ cases in summarizing session and providing feedback respectively. In other 5 fields the mean score ranged from 2.27 to 2.77 . Statistically highly significant differences were observed between the mean scores of observer's opinion and students' view in field of clarifying objective of the session and use of quality training aids $(p=0.000)$. Statistically highly significant $(p=0.000)$ differences were observed between the mean scores of observer's opinion, para-clinical students' view and pre-clinical students' view in field of gaining attention of the students at the beginning, clarifying objective of the session, exploring prior knowledge and use of quality training aids (Table-VII). Positive correlation between all the items in using teaching methodologies and benefit of the student was observed at a significance level 0.01 (Table-VIII).

Table-V: Distribution of teacher's performance on practicing instructional events by observer's opinion $(n=30)$.

\begin{tabular}{|l|c|c|c|c|c|c|}
\hline \multirow{2}{*}{ Teacher's performance } & \multicolumn{5}{|c|}{ Observer's opinion } \\
\cline { 2 - 7 } & $\begin{array}{c}\text { Excellent } \\
\mathrm{f}(\%)\end{array}$ & $\begin{array}{c}\text { Very good } \\
\mathrm{f}(\%)\end{array}$ & $\begin{array}{c}\text { Good } \\
\mathrm{f}(\%)\end{array}$ & $\begin{array}{c}\text { Satisfactory } \\
\mathrm{f}(\%)\end{array}$ & $\begin{array}{c}\text { Unsatisfactory } \\
\mathrm{f}(\%)\end{array}$ & $\begin{array}{c}\text { Score } \\
\text { Mean } \pm(\mathrm{SD})\end{array}$ \\
\hline Gaining attention & $7(23.3)$ & $5(16.7)$ & $10(33.3)$ & $5(16.7)$ & $3(10.0)$ & $2.27 \pm 1.29$ \\
\hline Objective of the lesson & $4(13.3)$ & $0(0.0)$ & $2(6.7)$ & $8(26.7)$ & $16(53.3)$ & $0.97 \pm 1.35$ \\
\hline Pre-requisite knowledge & $12(40.0)$ & $1(3.3)$ & $6(20.0)$ & $7(23.3)$ & $4(13.3)$ & $2.30 \pm 1.54$ \\
\hline Organization of the lecture & $12(40.0)$ & $4(13.3)$ & $9(30.0)$ & $3(10.0)$ & $2(6.7)$ & $2.70 \pm 1.29$ \\
\hline Sufficiency of teaching aids & $12(40.0)$ & $4(13.3)$ & $10(33.3)$ & $3(10.0)$ & $1(3.3)$ & $2.77 \pm 1.19$ \\
\hline Legibility of teaching aids & $7(23.3)$ & $2(6.7)$ & $7(23.3)$ & $6(20.0)$ & $8(26.7)$ & $1.80 \pm 1.51$ \\
\hline Feedback & $16(53.3)$ & $4(13.3)$ & $1(3.3)$ & $3(10.0)$ & $6(20.0)$ & $2.70 \pm 1.66$ \\
\hline Summary & $5(16.7)$ & $7(23.3)$ & $2(6.7)$ & $7(23.3)$ & $9(30.0)$ & $1.73 \pm 1.53$ \\
\hline
\end{tabular}

Note: Excellent $=4$, Very good=3, Good=2, Satisfactory $=1$, Unsatisfactory $=0$

Table-VI: Comparison of Mean (SD) score of observer's opinion and student's view on teacher's performance on practicing instructional events.

\begin{tabular}{|l|c|c|c|c|c|}
\hline Performance & $\begin{array}{c}\text { Observer's opinion } \\
\text { Mean } \pm \text { SD }\end{array}$ & $\begin{array}{c}\text { Student's views } \\
\text { Mean } \pm \text { SD }\end{array}$ & $\boldsymbol{t}$ & $\mathbf{d f}$ & $\mathbf{p}$ value \\
\hline Gaining attention & $2.27 \pm 1.29$ & $2.56 \pm 1.22$ & 1.30 & 1528 & 0.196 \\
\hline Objective of the session & $0.97 \pm 1.35$ & $2.49 \pm 1.20$ & 6.85 & 1528 & $0.000^{*}$ \\
\hline Pre requisite knowledge & $2.30 \pm 1.54$ & $2.52 \pm 1.41$ & 1.05 & 1528 & 0.295 \\
\hline Quality of teaching aids & $1.80 \pm 1.52$ & $2.93 \pm 1.15$ & 5.30 & 1528 & $0.000^{*}$ \\
\hline Feedback & $2.70 \pm 1.66$ & $2.57 \pm 1.28$ & 0.55 & 1528 & 0.585 \\
\hline Summary & $1.73 \pm 1.53$ & $2.03 \pm 1.26$ & 1.27 & 1528 & 0.204 \\
\hline
\end{tabular}

${ }^{*}$ Differences are significant statistically. 
Table-VII: Comparison of mean score among observer, para-clinical and pre-clinical students on teacher's performance on practicing instructional events.

\begin{tabular}{|c|c|c|c|c|}
\hline Performance & Category & Mean score & $\mathbf{F}$ & $\mathrm{p}$ value \\
\hline \multirow{3}{*}{ Gaining attention } & Observer & $2.27 \pm 1.29$ & \multirow{3}{*}{15.62} & \multirow{3}{*}{0.000} \\
\hline & Para-clinical & $2.73 \pm 1.15$ & & \\
\hline & Pre-clinical & $2.38 \pm 1.28$ & & \\
\hline \multirow{3}{*}{ Objective of the session } & Observer & $0.97 \pm 1.35$ & \multirow{3}{*}{37.428} & \multirow{3}{*}{0.000} \\
\hline & Para-clinical & $2.64 \pm 1.13$ & & \\
\hline & Pre-clinical & $2.32 \pm 1.25$ & & \\
\hline \multirow{3}{*}{ Prior knowledge } & Observer & $2.30 \pm 1.54$ & \multirow{3}{*}{15.796} & \multirow{3}{*}{0.000} \\
\hline & Para-clinical & $2.68 \pm 1.05$ & & \\
\hline & Pre-clinical & $2.36 \pm 1.20$ & & \\
\hline \multirow{3}{*}{ Quality of teaching aid } & Observer & $1.80 \pm 1.52$ & \multirow{3}{*}{14.500} & \multirow{3}{*}{0.000} \\
\hline & Para-clinical & $2.90 \pm 1.16$ & & \\
\hline & Pre-clinical & $2.96 \pm 1.15$ & & \\
\hline \multirow{3}{*}{ Feedback } & Observer & $2.70 \pm 1.66$ & \multirow{3}{*}{1.064} & \multirow{3}{*}{0.345} \\
\hline & Para-clinical & $2.61 \pm 1.26$ & & \\
\hline & Pre-clinical & $2.52 \pm 1.31$ & & \\
\hline \multirow{3}{*}{ Summary } & Observer & $1.73 \pm 1.53$ & \multirow{3}{*}{4.174} & \multirow{3}{*}{0.016} \\
\hline & Para-clinical & $2.11 \pm 1.27$ & & \\
\hline & Pre-clinical & $1.94 \pm 1.25$ & & \\
\hline
\end{tabular}

Note: $\mathrm{df}=2$

Table-VIII: Association relation between practicing instructional events and benefit of the student.

\begin{tabular}{|l|c|c|}
\hline Performance & r value & p value \\
\hline Gaining attention & 0.941 & 0.000 \\
\hline Mentioning objective & 0.923 & 0.000 \\
\hline Stimulating prior knowledge & 0.918 & 0.000 \\
\hline Legibility of teaching aids & 0.937 & 0.000 \\
\hline Feedback & 0.948 & 0.000 \\
\hline Summary provided by the teachers & 0.833 & 0.000 \\
\hline
\end{tabular}

\section{Discussion}

Gaining attention is the first event that teachers have to demonstrate for a successful instruction ${ }^{6}$. In this study, out of 1500 respondents $67 \%$ were towards agreement with the statement that teachers successfully gained attention at the beginning of the lecture; but, about one fourth $(23.1 \%)$ respondents disagreed in this regard. According to observer's opinion, about three fifth $(73.3 \%)$ of the teachers effectively gained attention (excellent, very good and good) and $10 \%$ teachers were unable in gaining attention with a mean score $2.27 \pm 1.29$. Mohammad SD found in a study that $30.6 \%$ teachers gained attention in their lectures ${ }^{7}$. Reasons for this variation may be that in recent time medical teachers are getting training in teaching methodologies and so equipped themselves more than before. In this study, there was no statistically significant difference $(p=0.196)$ between the mean scores of students' views and observer's opinion on gaining attention but significant difference $(p=0.000)$ was noticed between the scores of preclinical $(2.38 \pm 1.28)$ and paraclinical $(2.73 \pm 1.148)$ students. In mentioning objective, it was found that about two third (62.4\%) of the students were towards agreement and more than one fourth $(26.7 \%)$ were towards disagreement with the statement that the teachers clearly mentioned objectives at the beginning of the class with a mean score of $2.49 \pm 1.23$. Similar score (2.46) was noted in the study carried out by Nahar et $a^{8}$. Study carried out by Borker et al ${ }^{9}$ found mean score 2.17 for male and 2.34 for female and study of Rahman ${ }^{10}$ revealed the mean score as $2.29 \pm 1.12$. All these values are less than the findings of the present study. Mohammad $\mathrm{SD}^{7}$ in a study in Bangladesh found that $27.8 \%$ teachers did not mention learning objectives, which supports the finding of present study. In this study according to observer's opinion more than half $(53.3 \%)$ of the teachers were marked as unsatisfactory in mentioning objective with a mean score $0.97 \pm 1.35$ and there was significant difference $(p=0.000)$ between the mean score of students' view and observer's opinion in mentioning objective. The mean score of observer $(0.97 \pm 1.35)$ was less than 2 which indicates that mentioning objective by the teachers was unsatisfactory ${ }^{5,11}$.

About two third $(65.4 \%)$ of the respondents were towards agreement with the statement that the teachers inquired the prerequisite knowledge of students and about one fourth $(23.55 \%)$ were towards disagreement. In a study by Turkey Gulpinar et $\mathrm{al}^{12}$ found that $13.3 \%$ of the students disagreed that during the presentation prior knowledge was taken into consideration which was lower than the finding of the present study. Mohammad ${ }^{7}$ found that $66.7 \%$ of teachers correlated prior knowledge of the students with present topic which was similar to the finding of present study. Malik et $\mathrm{al}^{13}$ in their study in Pakistan found that $45 \%$ respondents disagreed that teachers evaluated previous knowledge which was higher than the findings of the present study. In stimulating prerequisite knowledge, the mean scores of observer $(2.30 \pm 1.54)$, preclinical students $(2.36 \pm 1.20)$ and paraclinical students $(2.68 \pm 1.05)$ were found between 2 and 3 , which indicate that this aspect could be enhanced ${ }^{5,14}$.

In this study, the observer opined that in $53.3 \%$ of the lecture classes the legibility of the teaching aids was good, very good and excellent with a mean score $1.80 \pm 1.51$. Mohammad ${ }^{7}$ observed that $36.1 \%$ visual aids were readable from the last bench which indicates that the quality of teaching aids has been 
improved in the present study. Statistical analysis showed that there was significant difference between the mean score of students' views and observer's opinion $(p=0.00)$ in this study. The score made by observer was less. This may be because the observer tried to score keeping in mind the theory of quality training aids and students paid importance on the visual impression only.

In the present study, the observer found that the most of the lectures $(53.3 \%)$ presented by the teachers were very well organized (Very good-Excellent) and $6.7 \%$ lectures were unsatisfactory in this regard. Mohammad ${ }^{7}$ observed that $41.7 \%$ lectures were very well organized and $25 \%$ lectures were not at all organized. It was found that though majority of the students $(65.8 \%)$ expressed their view that teachers took necessary feedback during the class but more than one fourth $(26.15 \%)$ of the student respondents were in the range of disagreement to the statement. In case of taking feedback, almost similar finding was noted by the observer where $20 \%$ teachers were found unsatisfactory in taking feedback. Mohammad ${ }^{7}$ found that $72.2 \%$ teachers took feedback during the lecture class which supports the finding of the present study. The mean scores of the observer (2.70 \pm 1.53$)$, preclinical students $(2.52 \pm 1.31$ and paraclinical students $(2.61 \pm 1.26)$ in taking feedback by the teachers did not show any statistically significant difference $(p=0.345)$. Nahar et $\mathrm{al}^{8}$ in their study in Bangladesh found 2.19 as the mean score, which is less than the scores of present study. Al-Hazimi et al $^{15}$ in their study in Saudi Arabia found the mean score in providing feedback by the teachers in three medical schools as 2.52, 2.27 and 1.71 which are also less than the scores of present study.

In present study, though more than $52.3 \%$ of the respondents were in the range of agreement that the teachers provided good summary at the end of the lesson, yet $41.9 \%$ respondents were towards disagreement to the statement. In the observer's finding it was noted that $30 \%$ of the teachers were unsatisfactory in providing summary at the end of the lesson. Sarker and Majumder ${ }^{16}$ in a study conducted in India found that $65.3 \%$ students viewed that summarization was not done by the teacher which is higher than the finding of the present study. Mohammad ${ }^{7}$ found that $50 \%$ of the teachers did not summarize the topic at the end of the lesson which indicates that the teachers performed better than the previous study in summarizing the topic. The mean score for providing summary by observer's opinion, preclinical students and paraclinical students were $1.73 \pm 1.53,1.94 \pm 1.25$ and $2.11 \pm 1.27$ respectively and the difference was statistically significant $(p=0.016)$. In this study positive correlation was found between the variables under instructional events and benefit of the lecture.

\section{Conclusion}

It is well documented that till to date lectures are being widely practiced in the different higher educational institutes. In this study, after analyzing different findings it is felt that the teachers of medical colleges may have been missing in practicing some important instructional events in their lecture classes. It is widely accepted that for any learning to take place the teachers must first capture the attention of the students. Attention motivates the students for learning. Mentioning the learning objectives initiates the internal process of expectancy and motivates the learner to complete the lesson. It is well known that associating the new information with the prior knowledge can facilitate the learning process. In a lecture, summarizing and linking help recall and understanding. This study revealed some of the key performance areas of the teachers like mentioning objective of the lesson, providing summary, quality of teaching aids had the score less than 2 indicating that those were the problem areas and recommended to examine more closely. In this regards, continued medical education/ continued professional developmental program of medical colleges need to be evaluated and exercised properly.

\section{References}

1. Harden RM, Crosby J. The Good Teacher is More Than a Lecture-the twelve roles of the teacher, AMEE Guide No 2, Dundee, UK: Association of Medical Education in Europe; 2000.

2. Gibbs G, Habeshaw S, Habeshaw T. Improving Student Learning in Lectures. Medical Teacher 1987; 9(1):11-20.

3. Manzoor I, Mumtaz A, Habib M et al. Lectures in Medical Education: Student's Views. J Ayub Med Coll Abbotabad 2011; 23(4);118-21. 
4. Mcmillan WJ. 2007. Then You Get a Teacher-Guidelines for Excellence in Teaching Medical Teacher 2007; 29(8): 209-18.

5. Mcaleer S, Roff S. A Practical Guide to Using the Dundee Ready Education Environment Measure (DREEM). AMEE Medical Education Guide No. 23, Curriculum, Environment, Climate, Quality and Change in Medical Education; a unifying perspective. Dnudee UK: Association of Medical Education in Europe; 2002. [www.gppro.co.uk/swacpo/document/dreem2.duc]

6. Gagne RM, Briggs LJ, Wager WW. Principles of Instruction Design, 4th ed. New York: Harcourt Brace Jovanovic College Publishers; 1992. p200-2.

7. Mohammad SD. A Situation Analysis of Current Large Group Teaching in Medical College in Dhaka city (Thesis). Dhaka : Centre For Medical Education; 2008.

8. Nahar N, Talukder MHK, Khan MTH et al. Students' Perception of Educational Environment of Medical Colleges in Bangladesh. Journal of BSMMU 2010; 3(2): 97-102.

9. Borker DRS, Meshram DSA, Jadhav DPE. Introducing Interactivity in Community Medicine Class for Arousing Interest in the Subjects amongst 2nd year MBBS Students. Research and Evaluation 2012; 4(36): 47-8.

10. Rahman AM. Perception of the Educational Environment of a New Medical School, Saudi Arabia. International Journal of Health Sciences 2013; 7(2): 150-9.
7. Gulpinar M, Yegen BC. Interactive Lecturing for Meaningful Learning in Large Groups. Medical Teacher 2005; 27(7): 590-4.

11. Taheri M. Students' Perception of Learning Environment in Guilan University of Medical Sciences. Journal of Medical Education 2009; 13(4):127-133.

12. Gulpinar M, Yegen BC. Interactive Lecturing for Meaningful Learning in Large Groups. Medical Teacher 2005; 27(7): 590-4.

13. Malik MA, Murtaza DA, Khan DAM. Role of Teachers in Managing Teaching Learning Situation. Interdisciplinary Journal of Contemporary Research in Business 2011; 3(5): 783-821.

14. Zawawi AH, Zubeir ME. Using DREEM to Compare Graduate Student's Perceptions of Learning Environment in Traditional and Innovative Medical Schools: A study in Four Undergraduate Medicla Schools. Education for Health 2004; 17(2): 192-203.

15. Al-Hazimi A, Zaini R, Al-Hyiani A et al. Educational Environment in Traditional and Innovative Medical Schools: A Study in Four Undergraduate Medical Schools. Education for Health 2004; 17(2): 192-203.

16. Sarker AP, Majumder G. Perception of Lecture in Community Medicine among Students of West Bengal in India. Reviews of Progress 2013; 1(17). 